\title{
Molecular Interaction Studies on Arylamine Containing Ternary organic Liquid Mixtures Using Ultrasonic Technique
}

\author{
R.Ezhil Pavai ${ }^{\mathrm{a}}$ and K.Kiruthika devi ${ }^{\mathrm{b}}$ \\ ${ }^{a}$ Department of Physics, Annamalai University, Tamilnadu, India. \\ ${ }^{b .}$ Physics section, Faculty of Engineering and Technology, Annamalai University, Tamilnadu, India.
}

\begin{abstract}
Ultrasonic velocity, density and viscosity have been measured for two ternary liquid mixtures of aniline+ toluene+ methyl isobutyl ketone and N-methylaniline+ toluene+ methyl isobutyl ketone at 303, 308 and $313 \mathrm{~K}$. From the measured data, the acoustical parameters such as adiabatic compressibility, free length, free volume, internal pressure, Gibb's free energy and their excess parameters were calculated. The obtained results support the occurrence of molecular association through intermolecular hydrogen bonding and the excess functions are found to be sensitive to the nature and extent of the interactions taking place in these ternary mixtures.
\end{abstract}

Keywords: Ternary liquid mixtures, acoustical parameters, molecular interaction.

\section{Introduction}

The study of molecular interaction plays a vital role in the development of molecular science. Ultrasonic waves have been used by many scientists to investigate the nature of molecular interaction and physico-chemical behaviors of pure, binary and ternary liquid mixtures [1,2]. Ultrasonic velocity along with density and viscosity data furnish wealth of information about interaction between ions, dipoles, hydrogen bonding, multipolar and dispersive forces [3-5].

Mixed solvent rather than single liquids are of almost practical importance in most chemical and industrial processes as they provide a wide range of mixtures of two or more components in varying proportions so as to permit continuous adjustment of desired properties of the medium. The mixing of different compounds gives rise to solutions that generally do not behave as ideal solutions. The deviation from ideality is expressed by many acoustical and thermodynamic variables particularly by excess or residual properties [6-9].

Excess parameters, which depend on the composition, temperature and pressure of the system, are of great importance to a chemical engineer in the design of industrial separation process and to a chemist for arriving at theories of liquid mixtures. Accurate knowledge of acoustical and thermodynamic properties of organic liquid mixtures has relevance in understanding the molecular interactions between the components of the mixture.

In the present work, an attempt to understand the molecular interaction in the ternary mixtures of aniline+toluene+methyl isobutyl ketone (MIBK) and N-methylaniline+toluene+methyl isobutyl ketone (MIBK) through ultrasonic velocity, density and viscosity measurements at 303, 308 and 313K. From these experimental data, adiabatic compressibility, free length, free volume, internal pressure, Gibb's free energy and their excess values have been calculated.

\section{Materials And Methods}

The liquid mixtures of various concentrations in mole fraction were prepared by taking purified AR grade chemicals. In both the systems, the mole fraction of second component, toluene was kept fixed (0.3), while the mole fractions of the remaining two were varied from 0.0 to 0.7 , so as to have the mixtures of different compositions. The ultrasonic velocity for the mixtures was measured using the ultrasonic interferometer (Mittal Enterprises, New Delhi) at fixed frequency of $2 \mathrm{MHz}$ with an accuracy of $\pm 0.1 \%$. The density and viscosity were measured using the specific gravity bottle and on Ostwald's viscometer respectively.

\section{Theory and calculation}

Using the measured data, the acoustic parameters such as adiabatic compressibility $(\beta)$, free length $\left(\mathrm{L}_{\mathrm{f}}\right)$, free volume $\left(\mathrm{V}_{\mathrm{f}}\right)$, internal pressure $\left(\pi_{\mathrm{i}}\right)$, Gibb's free energy $\left(\Delta \mathrm{G}^{*}\right)$ and their excess parameters have been calculated using the standard relations.

$$
\begin{gathered}
\beta=\frac{1}{\rho U^{2}} \\
L_{\mathrm{f}}=\mathrm{K}_{\mathrm{T}} \beta^{1 / 2}
\end{gathered}
$$




$$
\begin{aligned}
& \mathrm{V}_{\mathrm{f}}=\left[\frac{\mathrm{M}_{\text {eff }} \mathrm{U}}{\mathrm{K} \eta}\right]^{3 / 2} \\
& \pi_{\mathrm{i}}=\mathrm{bRT}\left[\frac{\mathrm{K} \eta}{\mathrm{U}}\right]^{1 / 2}\left[\frac{\rho^{2 / 3}}{\mathrm{M}_{\text {eff }}^{7 / 6}}\right] \\
& \Delta \mathrm{G}^{*}=-2.303 \mathrm{KT} \log \frac{\mathrm{h}}{\mathrm{KT} \tau}(5) \\
& \mathrm{A}^{\mathrm{E}}=\mathrm{A}_{\text {exp }}-\mathrm{A}_{\text {id }}
\end{aligned}
$$

The above notations have usual meanings.

\section{Results And Discussion}

Experimental values of density, viscosity and ultrasonic velocity for two ternary systems at different temperatures are show in Table 1. The adiabatic compressibility, free length and free volume are presented in Table 2. Table 3 shows the values of internal pressure and Gibb's free energy.

Figs. 3-7 show the variation of excess values of above said parameters in ternary systems with composition of arylamine. On analyzing the experimental and derived parameters, interesting observation has been obtained on the addition of arylamine with toluene and MIBK.

It is observed from Table1 that density, ultrasonic velocity and viscosity for both the ternary systems increase with increase in mole fraction of arylamine. The variation of these properties is different from ideal mixture behavior and this can be attributed to the molecular association and structural changes occurring in the systems $[10,11]$. The molecular association arises from hydrogen bonding between the components of mixtures. The increasing trend of experimental data reveals that the addition of arylamine makes the binary mixture to be more compact, thereby revealing the attractive type interaction between the components. All the mixture becomes more and more compact with the further addition of arylamine.

Also it is noted that the velocity of ultrasonic wave, density and viscosity decrease with increase of temperature. As the temperature is increased, the available thermal energy facilitates breaking of the bonds between the associated molecules into their monomers and hence increase in thermal energy weakens the molecular force which in turn decreases the measured data as excepted.

Arylamines are having relatively higher dielectric constant [12] and basically electron donor nature, when it mixes with MIBK exhibits significant interaction like a hydrogen bonding between the participating molecules. Aniline/ N-methylaniline molecules are highly polar and associated through hydrogen bond in their pure state [13] and MIBK is also self associated through dipole-dipole interaction [14] in the pure state. The mixing of aniline/N-methylaniline with MIBK tends to break the associate present in the aniline/ $\mathrm{N}$ methylaniline and MIBK species which results in the formation of new associated species which consists mainly of hydrogen bonding $(\mathrm{N}-\mathrm{H} \ldots \mathrm{O}=\mathrm{C})$ between hydrogen atom of aniline/N-methylaniline and oxygen atom of ketone molecules as depicted in Figs.1 and 2.

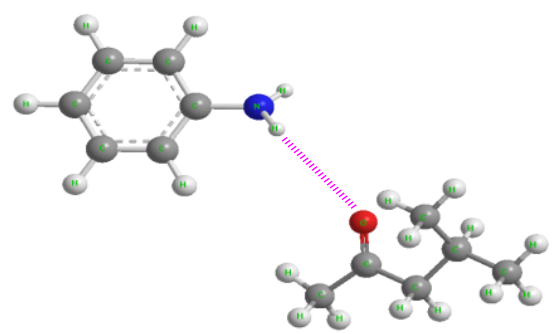

Fig.1 Hydrogen - bond formation between aniline and methyl isobutyl ketone molecules

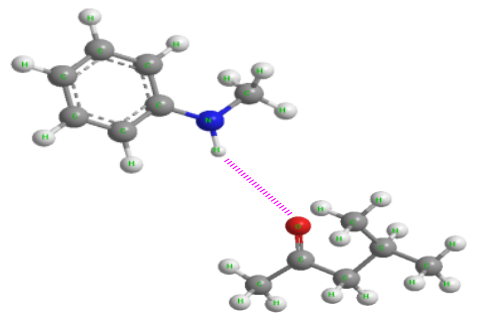

Fig.2 Hydrogen- bond formation between $\mathrm{N}$-methyl aniline and methyl isobutyl ketone molecules 
Molecular Interaction Studies on Arylamine Containing Ternary organic Liquid Mixtures..

On comparing both systems, the values of density, viscosity and velocity of aniline are greater than $\mathrm{N}$ methylaniline. This suggests that the molecular interaction is stronger in aniline system than in N-methylaniline system. This is due to the availability of more number of electrons on amino nitrogen in $\mathrm{N}$-methylaniline than aniline. So the dissociation of proton from the $\mathrm{N}$-methylaniline is less probable thereby weakening the hydrogen bonding interaction with the ketone.

The adiabatic compressibility and free length (Table 2) both have an inverse relationship with ultrasonic velocity. The decrease in adiabatic compressibility with increase in mole fraction is an indicative of the fact that intermolecular forces are increasing which brings the molecules to a closer packing resulting into a decrease in free length. Similar trend in adiabatic compressibility and free length has also been reported by Palaniappan [15].

Internal pressure in a liquid system is a measure of intermolecular cohesive forces [16]. From the Tables 2 and 3, it is observed that as the mole fraction of arylamine increases, free volume decreases whereas internal pressure increases. This suggests the close packing of the molecule inside the shield, which may be brought about by the increasing magnitude of interactions $[17,18]$.

Table 1. Density $(\rho)$, viscosity $(\eta)$ and velocity $(\mathrm{U})$ of arylamine + toluene+ MIBK

\begin{tabular}{|c|c|c|c|c|c|c|c|c|c|c|}
\hline \multirow{2}{*}{\multicolumn{2}{|c|}{ Mole fraction }} & $\rho \mathrm{kgm}^{-3}$ & & & $\eta \times 10^{3}$ & $\mathrm{sm}^{-2}$ & & $\mathrm{U} \mathrm{ms}^{-1}$ & & \\
\hline & & \multicolumn{9}{|c|}{ Aniline+toluene+MIBK } \\
\hline $\mathbf{X}_{1}$ & $\mathbf{X}_{3}$ & 303 & 308 & 313 & 303 & 308 & 313 & 303 & 308 & 313 \\
\hline 0.0000 & 0.7000 & 923.4 & 915.9 & 907.0 & 0.5575 & 0.4890 & 0.4302 & 1203.6 & 1191.5 & 1175.6 \\
\hline 0.0999 & 0.6000 & $\begin{array}{l}952.3 \\
\end{array}$ & 944.1 & $\begin{array}{l}933.2 \\
\end{array}$ & 0.6589 & 0.6071 & 0.5501 & 1238.4 & 1227.2 & 1213.1 \\
\hline 0.2000 & 0.5000 & 978.1 & 966.3 & 955.6 & 0.8391 & 0.7645 & 0.7013 & 1266.2 & 1255.0 & 1242.4 \\
\hline 0.3000 & 0.3999 & 1004.0 & 990.2 & 978.8 & 0.9716 & 0.8908 & 0.8018 & 1307.0 & 1294.1 & 1280.0 \\
\hline 0.4000 & 0.3000 & 1031.2 & 1019.0 & 1008.4 & 1.0992 & 0.9989 & 0.9102 & 1348.1 & 1331.7 & 1319.8 \\
\hline 0.4999 & 0.2000 & 1060.4 & 1048.4 & 1038.0 & 1.2968 & 1.1641 & 1.0608 & 1391.8 & 1376.4 & 1364.9 \\
\hline 0.5999 & 0.1000 & 1090.1 & 1078.0 & 1065.3 & 1.4748 & 1.3515 & 1.2085 & 1436.6 & 1425.5 & 1411.0 \\
\hline 0.6999 & 0.0000 & 1111.4 & 1099.2 & 1089.1 & 1.6718 & 1.5201 & 1.3642 & 1491.0 & 1477.2 & 1460.2 \\
\hline \multicolumn{11}{|c|}{ N- methylaniline+toluene+MIBK } \\
\hline 0.0000 & 0.7000 & 923.42 & 915.98 & 907.08 & 0.5575 & 0.489 & 0.4302 & 1203.6 & 1191.5 & 1175.6 \\
\hline 0.0999 & 0.6000 & 948.48 & 939.45 & 930.08 & 0.6012 & 0.5392 & 0.4864 & 1230.0 & 1216.4 & 1203.0 \\
\hline 0.2000 & 0.5000 & 972.06 & 960.00 & 948.45 & 0.7192 & 0.6537 & 0.5837 & 1261.5 & 1251.2 & 1239.2 \\
\hline 0.3000 & 0.3999 & 993.35 & 980.54 & 969.12 & 0.7892 & 0.7214 & 0.6564 & 1293.8 & 1280.6 & 1268.4 \\
\hline 0.4000 & 0.3000 & 1015.09 & 1007.42 & 999.04 & 0.8672 & 0.8048 & 0.7518 & 1330.1 & 1317.1 & 1303.0 \\
\hline 0.4999 & 0.2000 & 1036.42 & 1023.21 & 1012.00 & 0.9982 & 0.9286 & 0.8641 & 1363.0 & 1350.5 & 1338.6 \\
\hline 0.5999 & 0.1000 & 1060.38 & 1049.3 & 1038.04 & 1.1648 & 1.0702 & 0.9823 & 1408.2 & 1395.2 & 1379.2 \\
\hline 0.6999 & 0.0000 & 1086.51 & 1077.23 & 1064.12 & 1.3032 & 1.1993 & 1.1015 & 1452.6 & 1440.8 & 1429.5 \\
\hline
\end{tabular}

Table 2. Adiabatic compressibility $(\beta)$, free length $\left(\mathrm{L}_{\mathrm{f}}\right)$ and free volume $\left(\mathrm{V}_{\mathrm{f}}\right)$ of arylamine + toluene+ MIBK

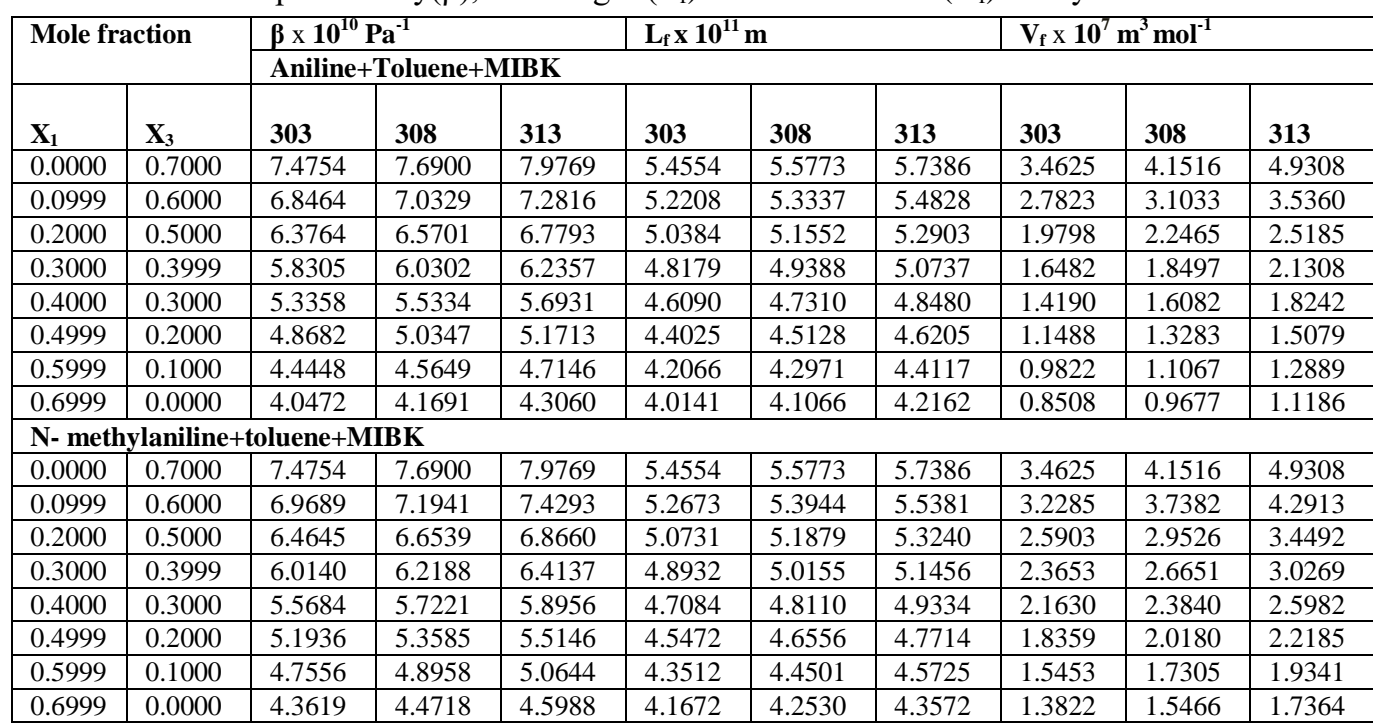

Table 3.Internal pressure $\left(\pi_{\mathrm{i}}\right)$ and Gibb's free energy $\left(\Delta \mathrm{G}^{*}\right)$ of arylamine + toluene+ MIBK

\begin{tabular}{|l|l|l|l|l|l|l|}
\hline \multicolumn{2}{|l|}{ Mole fraction } & \multicolumn{4}{|l|}{$\pi_{\mathrm{i}} \mathbf{X 1 0}^{-6} \mathrm{~Pa}$} & \multicolumn{3}{l|}{$\Delta \mathrm{G}^{*} \times 10^{20} \mathrm{kJmol}^{-1}$} \\
\cline { 3 - 7 } & Aniline+toluene+MIBK & 308 & 313 \\
\hline$X_{1}$ & $X_{3}$ & 303 & 308 & 313 & 303 & 308 \\
\hline
\end{tabular}


Molecular Interaction Studies on Arylamine Containing Ternary organic Liquid Mixtures..

\begin{tabular}{|l|l|l|l|l|l|l|l|}
\hline 0.0000 & 0.7000 & 517.02 & 488.46 & 462.48 & 0.5247 & 0.4967 & 0.4722 \\
\hline 0.0999 & 0.6000 & 575.25 & 558.12 & 536.00 & 0.5579 & 0.5507 & 0.5390 \\
\hline 0.2000 & 0.5000 & 667.91 & 642.39 & 620.89 & 0.6292 & 0.6197 & 0.6130 \\
\hline 0.3000 & 0.3999 & 731.06 & 705.23 & 674.55 & 0.6531 & 0.6483 & 0.6347 \\
\hline 0.4000 & 0.3000 & 790.60 & 760.87 & 732.52 & 0.6676 & 0.6604 & 0.6502 \\
\hline 0.4999 & 0.2000 & 875.56 & 836.64 & 805.50 & 0.6984 & 0.6853 & 0.6748 \\
\hline 0.5999 & 0.1000 & 949.94 & 916.67 & 873.09 & 0.7142 & 0.7071 & 0.6912 \\
\hline 0.6999 & 0.0000 & 1020.03 & 980.90 & 938.54 & 0.7274 & 0.7185 & 0.7044 \\
\hline \multicolumn{7}{|l|}{ N- methylaniline+toluene+MIBK } \\
\hline 0.0000 & 0.7000 & 517.02 & 488.46 & 462.48 & 0.5247 & 0.4967 & 0.4722 \\
\hline 0.0999 & 0.6000 & 537.97 & 514.42 & 493.20 & 0.5379 & 0.5099 & 0.4945 \\
\hline 0.2000 & 0.5000 & 591.23 & 567.55 & 539.85 & 0.5705 & 0.5585 & 0.5392 \\
\hline 0.3000 & 0.3999 & 617.93 & 595.55 & 572.62 & 0.5791 & 0.5717 & 0.5605 \\
\hline 0.4000 & 0.3000 & 645.50 & 629.55 & 616.08 & 0.5863 & 0.5828 & 0.5827 \\
\hline 0.4999 & 0.2000 & 692.97 & 674.14 & 656.42 & 0.6160 & 0.6157 & 0.6140 \\
\hline 0.5999 & 0.1000 & 747.28 & 723.08 & 699.85 & 0.6437 & 0.6377 & 0.6326 \\
\hline 0.6999 & 0.0000 & 788.60 & 764.27 & 737.74 & 0.6546 & 0.6476 & 0.6404 \\
\hline
\end{tabular}

In both the systems, an increase in free volume and decrease in internal pressure with increase of temperature is noted. This may be explained that there is a tendency for the solute molecules to move away from each other, reducing the possibility for interaction, which may further reduce the cohesive force and ultimately lead to an increase in free volume [19]. The increasing positive values of Gibb's function indicate that the closer approach of unlike molecules $[20,21]$ and also suggests shorter time for rearrangement of the molecules in the mixtures.

In order to understand more about the nature of interactions between the components of the liquid mixtures, it is necessary to discuss the same in terms of excess parameters rather than actual values. Non-ideal liquid mixtures show considerable deviation from linearity in their physical behavior with respect to concentration and temperature and these have been interpreted as arising from the presence of strong or weak interactions [22].

The values of excess adiabatic compressibility are negative over the entire mole fraction of arylamine. This may be qualitatively interpreted in terms of closer approach of unlike molecules leading to reduction in compressibility and volume [23,24]. Roshan Abraham et al., [25] have reported that negative excess compressibility is an indication of strong interaction in liquid mixtures, which is attributed to hydrogen bond, charge transfer, dipole - induced dipole and dipole - dipole interactions and hence support the present investigation.

The excess free length $\left(\mathrm{L}_{\mathrm{f}}^{\mathrm{E}}\right)$ is plotted against the mole fraction of arylamine in the ternary systems is shown in Fig. 4. The negative deviations suggest the existence of strong interaction due to the formation of hydrogen bond [26].

Variation in excess free volume $\left(\mathrm{V}_{\mathrm{f}}^{\mathrm{E}}\right)$ and internal pressure $\left(\pi_{\mathrm{i}}^{\mathrm{E}}\right)$ of arylamine in the ternary systems at different temperatures is shown in Figs. 5 and 6. The excess free volume is found to be almost negative over the entire mole fraction of the mixtures in both systems. Negative deviations in $\mathrm{V}_{\mathrm{f}}^{\mathrm{E}}$ suggest the presence of strong interaction between hydrogen atom of aniline/ $\mathrm{N}$-methylaniline and oxygen atom of ketone molecules. Similar results have also been drawn in a variety of liquid mixtures [27 - 29]. The excess internal pressure values have been forced to be almost positive for aniline system while $\pi_{i}^{\mathrm{E}}$ is completely positive throughout the mole fraction of $\mathrm{N}$-methylaniline. The positive values of $\pi_{\mathrm{i}}^{\mathrm{E}}$ indicate strong interaction between the component molecules [30].

Fig.3. Excess adiabatic compressibility of Vs mole fraction of arylamine
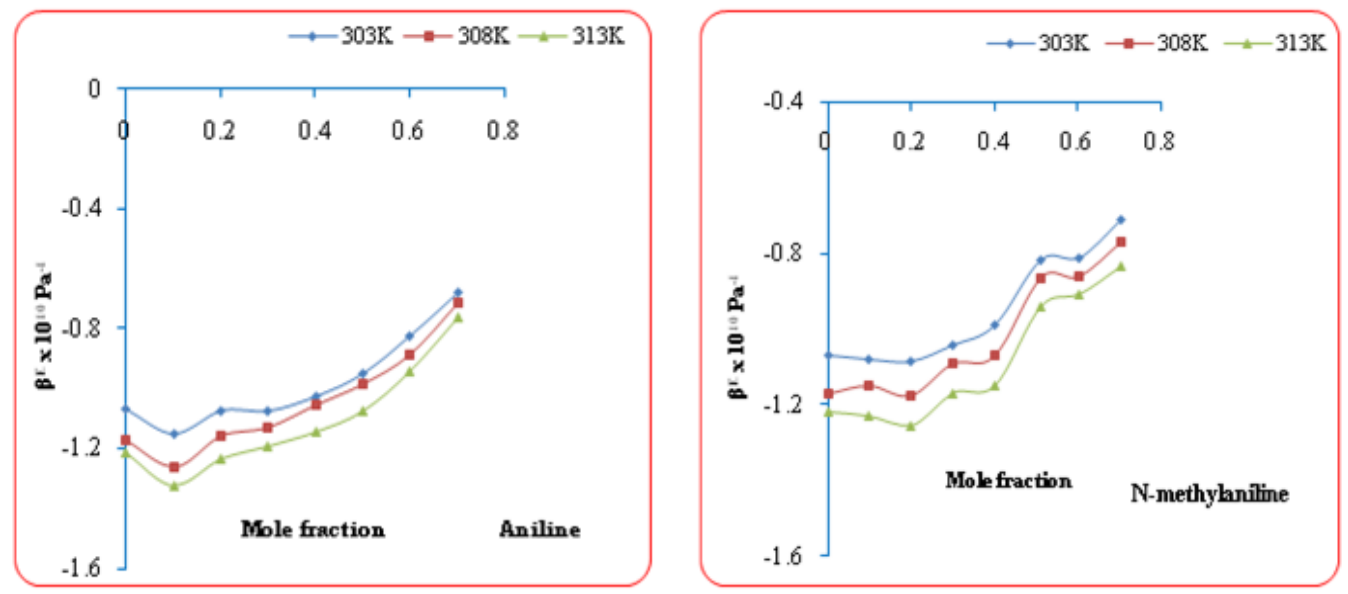
Fig.4. Excess free length Vs mole fraction of arylamine
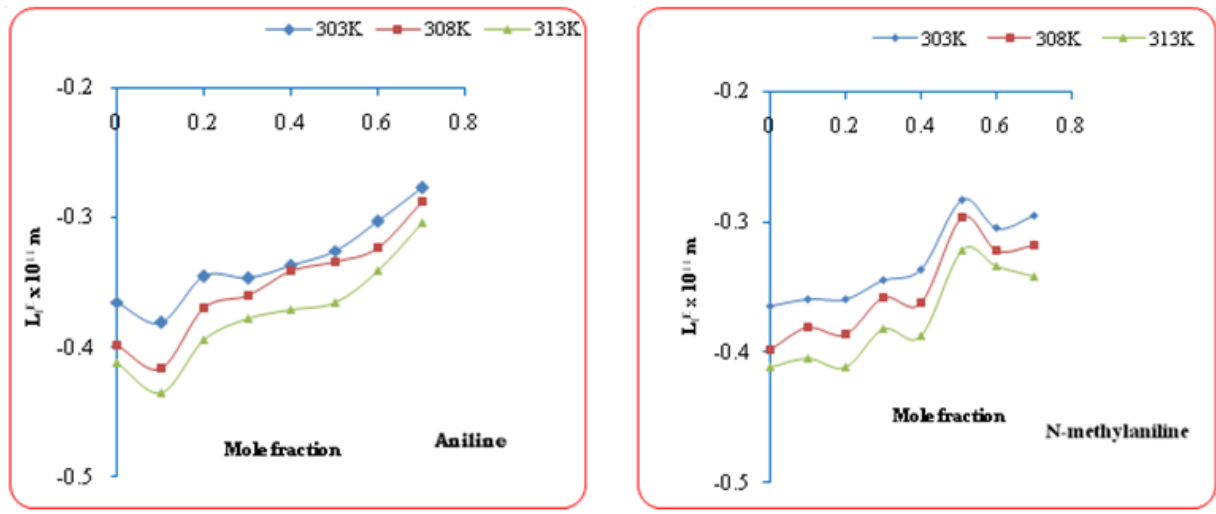

Fig.5. Excess free volume Vs mole fraction of arylamine
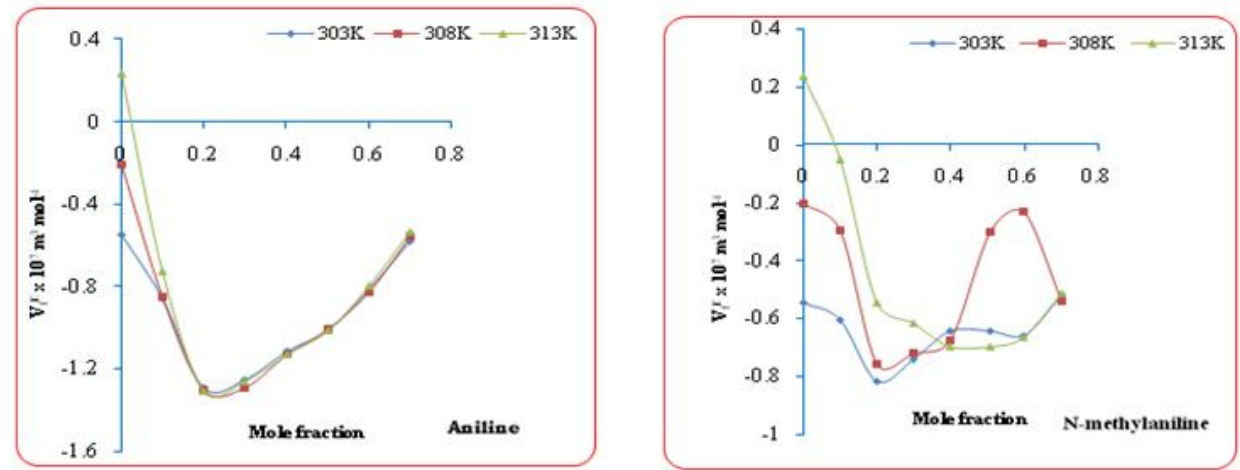

Fig.6. Excess internal pressure Vs mole fraction of arylamine
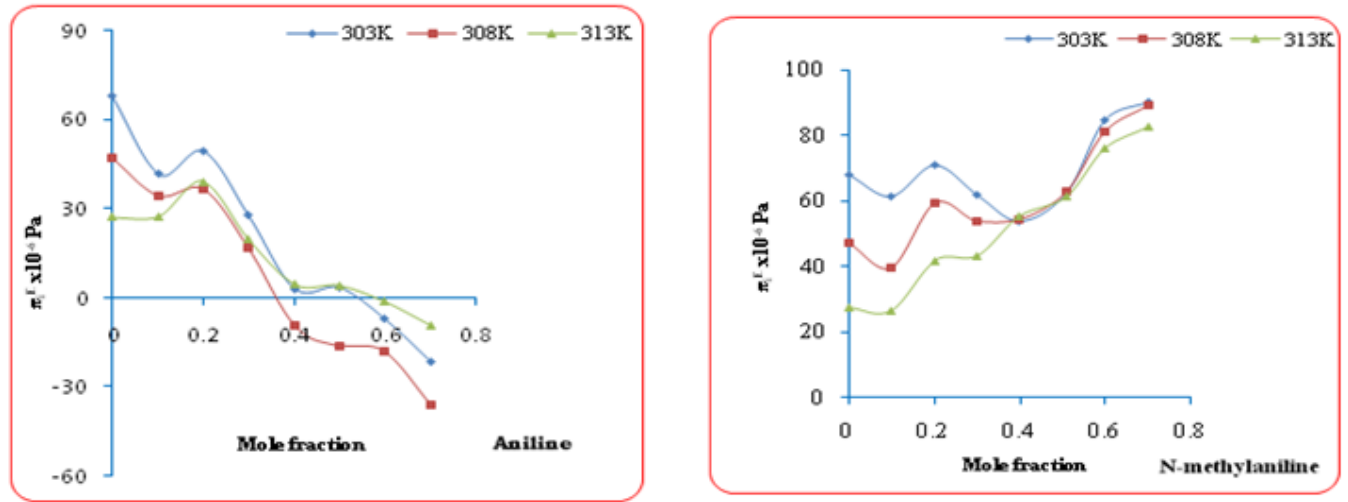

Fig.7. Excess Gibb's free energy Vs mole fraction of arylamine
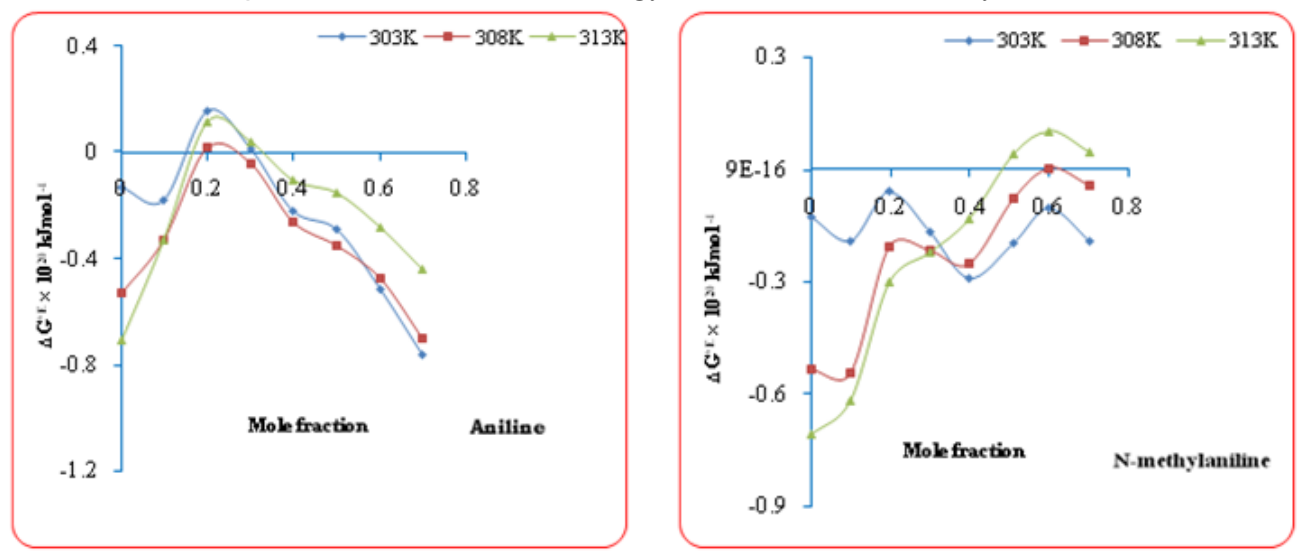
The small positive and negative values of Gibb's free energy support the above views.

\section{Conclusion}

On the basis of experimental and evaluated parameters for the two ternary systems, it is concluded that there exists strong molecular interaction between the mixing components. Molecular interaction is due to the formation of hydrogen bonding through hydrogen atom of aniline/ $\mathrm{N}$-methylaniline and oxygen atom of ketone. The strength of interaction varies in the order: aniline > N-methylaniline.

\section{References}

[1]. A.K.Dash and R.Paikaray, (2014). Der Chem. Sinica, Vol.5,no.1,

[2]. Steevi Felixa, Uma Sivakami and Rose Venis, (2016). World J.Pharmacy \& Pharmaceutical Sciences, Vol.5, Issue 5.

[3]. M.K.Praharaj, A.Satapathy, S.Mishra and P.R.Mishra, (2012) J.Chem. \& Pharmaceutical Research, 4(4) 1910.

[4]. T. Savitha Jyostna, and N.Satyanarayana, (2005) Ind. J. Chem., 444: 1365.

[5]. D.R.Bhadja,Y.V. Patel and P.H.Parasonia, (2002) Ind. J. Pure \& Appl. Phys., 24:47.

[6]. K.Rajagopal and S.Chenthilnath, (2010) Chinese J. Chem. Engg., 18(5): 804.

[7]. J.Viswanadha Sastry, K. Samatha and A.Viswanatha Sharma, (2003) J. Pure Appl. Ultrason., $25: 109$. J.Ortega, (1985) J. Chem. Engg. Data, 30: 465.

[9]. N.V.Sastry and M.K. Valand, (1997) Int. J. Thermophy., 18: 1387.

[10]. A.Sadasiva Rao, B.Vijayakumar Naidu and Chowdoji Rao, (2000) J. Acoust. Soc. Ind.,2: 301.

[11]. R.Ezhil Pavai, S.Renuka, L.Balu and P.Vasantharani, (2010) J. Expt. Sciences, 1: 21.

[12]. M. Aravinthraj, N. Dineshbabu, R. Kubendran, S.Venkatesan, and F.Liakath Ali Khan, (2011). Archives of physics research, 2(1).

[13]. N.Reisco, S. Villa, J.A.Gonzalez, I.G.De La Fuente and J.C.Cobos, (2002) Fluid Phase Equilib., 202 :345.

[14]. M.Radhamma, P.Venkatesu, M.Prabhakara Rao, and D.H.L.Prasad, (2007) J. Chem. Thermodyn., $39: 1991$.

[15]. L.Palaniappan, (2008) Physica B, 403: 3887.

[16]. S.Govindarajan, Venu Kannappan, M.D.Naresh, K.Venkataboopathy, and B.Lokanadan, (2003) B. J. Mol. Liqs., 107: 289.

[17]. U.Srinivasulu and P.R.Naidu, (1995) J. Pure Appl. Ultrason., 17 :123.

[18]. P.Vasantharani, L.Balu, R.Ezhil Pavai and S.Shailajha, (2009) Global J.Mol.Sciences, 4(1).

[19]. S.Jayakumar, M.Peer Mohammad, U.Ponnambalam, V.Kannappan, N.Karunanidhi, D.Subramaniyan, and N.M. Nataraj, (2002) J. Acoust. Soc. Ind., 30: 84

[20]. R.J. Fort and W.R. Moore, (1965) Trans. Faraday Soc., 61:2102.

[21]. Amalendu Pal, Harsh Kumar, B.R.Arbad and A.B.Takel (2003) Ind. J. Pure \& Appl. Phys., 41: 113

[22]. L.Balu, (2010) Ph.D. Thesis, Dept. of Physics, Annamalai University

[23]. S.S.Yadava and A.Yadava, (2005) Ultrason., 43: 732.

[24]. S.Muthu shailaja, (2008) Ph.D. Thesis, Dept. of Physics, Annamalai University

[25]. Roshan Abraham, J.Jugan and M.Abdul khadar, (1996) J. Pure Appl. Ultrason., $18: 114$

[26]. S.L.Oswal, V.Pandian, B.Krishnakumar, and P.Vasantharani, (2010) Thermochimica Acta, 507-508: 27.

[27]. J.Nath and Rashmi, (1999) J. Chem. Soc. Faraday Trans., 83399.

[28]. T.M.Aminabhavi, M.I.Aralaguppi, S.S.Joshi, R.S.Haragoppal, Khianrvar and R.H. Balundgi, (1992) Ind. J. Tech., $30: 303$.

[29]. T.Sathyarayana Rao, N.Veeraiah, G.Srinivasa Rao, D.Ramachandran, (2003) and C.Ramababu, J. Pure Appl. Ultrason., 25 : 38.

[30]. AN.Kannappan and V.Rajendran, (1992) Ind. J. Pure \& Appl. Phys., $30: 240$

[31]. R.J. Fort and W.R. Moore, (1965) Trans. Faraday Soc., 612102.

[32]. Amalendu Pal, Harsh Kumar, B.R.Arbad and A.B.Takel(2003) Ind. J. Pure \& Appl. Phys., 41113. 